\title{
A Study of Risk Factors of Clinically Significant Macular Edema in Diabetic Individuals
}

\author{
Dr. P.Rajasekhar ${ }^{1}$,Dr.M.Parni Kumar ${ }^{2}$ Dr.J.Sahithi ${ }^{3}$ \\ ${ }^{1}$ Assistant Professor,Department Of Ophthalmology, Guntur Medical College \\ ${ }^{2}$ Professor And H.O.D, Department Of Ophthalmology, Guntur Medical College \\ ${ }^{3}$ Senior Resident, Department Of Ophthalmology, Guntur Medical College
}

\begin{abstract}
To study the incidence of CSME in diabetic retinopathy \& association of CSME with risk factors like duration of diabetes, glycemic control, hypertension, hypercholesterolemia, anemia and nephropathy, an observational cross sectional study was conducted over a period of 6 months in 96 patients of diabetic retinopathy. After recording blood pressure, blood investigations were done and the significance of risk factors was compared in both the groups [with CSME and without CSME]. Mean Duration of Diabetes among the CSME group (10.61 4.259 years) was significantly higher than the non-CSME group (7.60 \pm 3.65 years). Serum cholesterol in the CSME group [241.76 $\pm 13.021 \mathrm{mg} \%]$ was significantly higher compared to the nonCSME group [187.52 $\pm 10.465 \mathrm{mg} \%]$. Serum LDL in the CSME group [139.79 $\pm 13.291 \mathrm{mg} \%$ ] was significantly

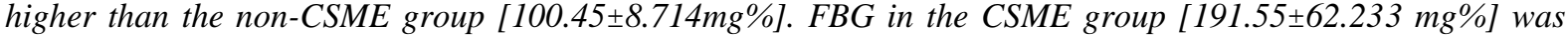
significantly higher compared to the non-CSME group [145.5 $50.311 \mathrm{mg} \%]$. Glycosylated haemoglobin, HbAlc was significantly higher in the CSME group [9.19 $\pm 0.919 \mathrm{mmol} / \mathrm{L}]$ as compared to the non-CSME group $[7.38 \pm 0.834 \mathrm{mmol} / \mathrm{L}]$. The haemoglobin level was lower in the CSME group [9.61 $\pm 0.608 \mathrm{~g} \%]$ as compared to the non-CSME group [11.15 $\pm 0.770 \mathrm{~g} \%]$. The urea and creatinine level were significantly higher in the CSME

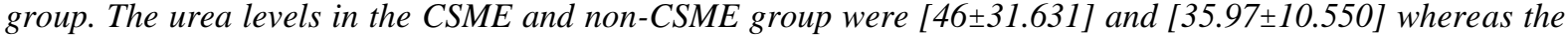
creatinine levels were $[1.32 \pm 0.778 \mathrm{mmol} / \mathrm{L}]$ and $[0.91 \pm 0.299 \mathrm{mmol} / \mathrm{L}]$ respectively. In conclusion, high cholesterol and high HbAlc levels were the two most important risk factors that lead to the development of CSME in this study. Anemia and low hematocrit have been found to be associated with microvascular complications including diabetic macular oedema. Serum urea and creatinine level, which reflects the renal function, were significantly higher in the CSME group
\end{abstract}

Keywords: Clinically significant macular oedema [CSME], Diabetic retinopathy,

\section{Introduction}

Diabetic retinopathy is one of the most common causes of blindness all over the world [1]. Diabetic macular edema is the most common cause of visual morbidity in diabetic patients. Although spontaneous recovery is not uncommon, $24 \%$ of eyes with clinically significant macular edema (CSME) will have a moderate visual loss (15 or more letters on the ETDRS chart) within 3 years if untreated [2].As the severity of overall retinopathy increases, the proportion of eyes with macular edema also increases, $3 \%$ in eyes with mild NPDR, 38\% with moderate NPDR and 71\% with PDR. Early intervention with laser photocoagulation can reduce the risk of vision loss by $50 \%$ or more and increases the chance of some improvement in visual acuity [3]. To study the incidence of CSME in diabetic retinopathy \& association of CSME with risk factors like duration of diabetes, glycemic control, hypertension, hypercholesteremia, anemia and nephropathy.

\section{Methodology}

The current study who attending at Out Patient Department, Ophthalmology, government general hospital, is an observational cross sectional study conducted over a period of 6 months [June 2016 to December 2016] in a sample of 96 patients diagnosed as having certain degree of diabetic retinopathy among diabetic individuals Guntur. Patients with other intraocular diseases like significant corneal opacity, Cataracts, ARMD and Glaucoma were excluded from the study After obtaining approval of the Institutional Ethics Committee, a written/informed consent was taken from patients in his/her vernacular language. A thorough clinical history was taken regarding complaints, duration of diabetes and other systemic diseases and also the treatment history.

A complete ophthalmic examination of the patients was done at presentation including visual acuity, Anterior segment examination with slit lamp, IOP measurement, by Applanation, Fundus examination by Direct and indirect ophthalmoscopy, Slit lamp biomicroscopy using 78D or 90D and Fundus photography . Fundus Fluorescein angiography and optical coherence tomography were done in some cases whenever indicated. After Fundus examination, only patients having retinopathy and CSME were selected for the study. 
Assessment of Clinically Significant Macular Edema (CSME)

Clinically Significant Macular Edema was defined in accordance with the ETDR Study (Early Treatment Diabetic Retinopathy Study Research Group,1985) by the presence of a set of characteristics:

- Retinal thickening at or within $500 \mu \mathrm{m}$ of the centre of the macula

- Hard exudates at or within $500 \mu \mathrm{m}$ of the macula, if associated with thickening of adjacent retina,

- Zones of retinal thickening one disc diameter or larger, any part of which is within one disc diameter of the centre of the macula.

\section{Results}

In the present observational cross sectional study conducted over a period of 6 months, 96 patients were included after satisfying the inclusion and exclusion criteria who were attending the outpatient department of Government General Hospital, Guntur. All of them underwent detailed ophthalmic and fundus examination and divided into 2 groups based on the presence or absence of CSME irrespective of the severity and grading of diabetic retinopathy. Age of the patients included in the study ranged between 10 and 76 years. The mean age of patients included in the study is $46.2 \pm 15.15$ years. Male population was more in the present study than female population. Out of the 96 patients studied, 13 patients were Type 1 and 83patients were Type 2 diabetics. In Type 1 diabetes, 25\% were having CSME and in Type 2diabetes, 42.2\% were having CSME. Out of 96 patients included in the present study, 57 are NPDR patients and 39patients are classified as having PDR. 29.82\% of NPDR patients and 53.84\% of PDR patients had CSME. Mean Duration of Diabetes among the CSME group (10.61 \pm 4.259 years) was significantly higher than the non-CSME group (7.60 \pm 3.65 years). Serum cholesterol in the CSME group $[241.76 \pm 13.021 \mathrm{mg} \%]$ was significantly higher compared to the non-CSME group $[187.52 \pm 10.465 \mathrm{mg} \%]$. Serum LDL in the CSME group [139.79 $\pm 13.291 \mathrm{mg} \%]$ was significantly higher than the non-CSME group [100.45 $\pm 8.714 \mathrm{mg} \%]$. FBG in the CSME group [191.55 $\pm 62.233 \mathrm{mg} \%$ ] was significantly higher compared to the non-CSME group [145.5 $\pm 50.311 \mathrm{mg} \%$ ]. Glycosylated hemoglobin, HbA1c was significantly higher in the CSME group $[9.19 \pm 0.919 \mathrm{mmol} / \mathrm{L}]$ as compared to the non-CSME group $[7.38 \pm 0.834 \mathrm{mmol} / \mathrm{L}]$. The hemoglobin level was lower in the CSME group $[9.61 \pm 0.608 \mathrm{~g} \%]$ as compared to the non-CSME group [11.15 $\pm 0.770 \mathrm{~g} \%]$. The urea and creatinine level were significantly higher in the CSME group. The urea levels in the CSME and non-CSME group were [46 \pm 31.631$]$ and [35.97 \pm 10.550$]$ whereas the creatinine levels were $[1.32 \pm 0.778 \mathrm{mmol} / \mathrm{L}]$ and $[0.91 \pm 0.299 \mathrm{mmol} / \mathrm{L}]$ respectively.

Table no.1: Risk factors in CSME and NON- CSME groups

\begin{tabular}{|l|l|l|l|l|}
\hline S.No & Risk factors & With CSME & Without CSME & P-value \\
\hline 1 & $\begin{array}{l}\text { Duration of DM( in } \\
\text { Years) }\end{array}$ & $10.61 \pm 4.259$ & $7.60 \pm 3.651$ & 0.00 \\
\hline 2 & FBG (mg\%) & $191.55 \pm 62.233$ & $145.5 \pm 50.311$ & 0.00 \\
\hline 3 & Hb A1c [\%] & $9.19 \pm 0.919$ & $7.38 \pm 0.834$ & 0.00 \\
\hline 4 & Haemoglobin $(\mathrm{g} \%)$ & $9.61 \pm 0.608$ & $11.15 \pm 0.770$ & 0.00 \\
\hline 5 & Systolic BP $(\mathrm{mm} \mathrm{Hg})$ & $144.95 \pm 14.366$ & $139.91 \pm 12.380$ & 0.071 \\
\hline 6 & Diastolic BP $(\mathrm{mm} \mathrm{Hg})$ & $83.11 \pm 9.320$ & $80.60 \pm 8.235$ & 0.17 \\
\hline 7 & Blood Urea [mg\%] & $46 \pm 31.631$ & $35.97 \pm 10.550$ & 0.028 \\
\hline 8 & $\begin{array}{l}7 \text { Serum Creatinine } \\
\text { [mmol/1] }\end{array}$ & $1.32 \pm 0.778$ & $0.91 \pm 0.299$ & 0.00 \\
\hline 9 & Total Cholesterol [mg\%] & $241.76 \pm 13.021$ & $187.52 \pm 10.465$ & 0.00 \\
\hline 10 & LDL[mg\%] & $139.79 \pm 13.291$ & $100.45 \pm 8.714$ & 0.00 \\
\hline
\end{tabular}

\section{Discussion}

This hospital based observational study was carried out to evaluate the prevalence \& risk factors for CSME. In the current study, 96 patients were included in the study.38 patients were found to have CSME. The age and sex distribution, association with the risk factors like duration of diabetes, HbA1C, FBG, Hb, cholesterol [TCL and LDL], serum creatinine and BUN were compared in between CSME and Non CSME groups. Age of the patients included in the study ranged between 10 and 76 years. The mean age of patients included in the study is $46.2 \pm 15.15$ years .In Peyman et al study [4], the mean age was58.20 \pm 7.07 years and in Sachdev et al.[5] study it was 55.6 \pm 7.4 years. In present study Diabetic retinopathy was more prevalent in males than females. The Sex distribution in the present study coincides with that of Sachdev et al[5] study. Duration of diabetes in this study was found to be significantly higher with the mean value of $10.61 \pm 4.259$ years in CSME group. The results are close to the Peyman et al[4] and Sachdev et al[5] studies.

The duration of diabetes in this study was found to be significantly higher in CSME group. The importance of diabetes duration was also demonstrated by the Wisconsin Epidemiological study of Retinopathy data which showed an increased prevalence of diabetic maculopathy of $28 \%$ in patients whose age at the time of diagnosis was 30 years or older and whose diabetes duration was 20 years or longer. HbA1C was found to be 
significantly higher in the CSME group in present study with the mean value of $9.19 \pm 0.919 \%$.The results correlate with the HbA1C values of Peyman et al and Sachdev et al studies. Fasting blood glucose levels were significantly higher in the present study in CSME group with the mean value of $191.55 \pm 62.233 \mathrm{mg} / \mathrm{dl}$. The results are close to the FBG levels of Peyman et al[4]. Total cholesterol [TCL] and LDL were significantly higher in CSME group in this study with the mean TCL of $241.76 \pm 13.021 \mathrm{mg} / \mathrm{dl}$ and the mean LDL of $139.79 \pm 13.291 \mathrm{mg} / \mathrm{dl}$. The results correlate with the TCL and LDL of Sachdev et al study. There was significant association between nephropathy and CSME in the present study. The mean value of serum creatinine in CSME group was $1.32 \pm 0.778 \mathrm{mmol} / \mathrm{l}$, which correlates with the serum creatinine levels of Peyman et al and Sachdev et al[ $[4,5]$.

\section{Conclusions}

Diabetic macular edema is the major cause of central vision loss among patients with diabetic retinopathy. The amount of visual loss will be significantly higher in case of patients with CSME. The incidence of CSME is increases in cases of length of diabetic duration, poor glycemic control and other Systemic factors such as fluid retention and hypertension had been implicated in the development of macula edema too.Many studies had been done to identify the risk factors or associations of diabetic macular edema. However, the associations varied from one study to another. The variation in the result may be due to epidemiological differences. Duration of diabetes, glycemic control, lipid profiles, hypertension and nephropathy were the few main risk factors found to be associated with increased risk of retinopathy and macular edema. The presence of diabetic maculopathy was found to be associated with diabetes duration in either type of diabetes. The importance of diabetes duration was also demonstrated by the Wisconsin Epidemiologic Study of Retinopathy data In conclusion, high cholesterol and high HbAlc levels were the two most important risk factors that lead to the development of CSME in this study. This result was consistent with most previous studies underlining the need for better glycemic and lipid control in the prevention of diabetic macular edema. Anemia and low hematocrit have been found to be associated with microvascular complications including diabetic macular edema. In this study, the CSME group was found to have lower hemoglobin level. Anemia may lead to progression of diabetic retinopathy by aggravating hypoxia in the retina, which then results in production of growth factors such as vascular endothelial growth factor. Serum urea and creatinine level, which reflects the renal function, were significantly higher in the CSME group. All these findings were consistent with the previous studies which has identified nephropathy as one of the association for macular edema.

\section{References}

[1]. Wild S.Roglic G, Green A et al, Global prevalence of diabetes, estimates for the year 200 and projections for 2030.Diabetes Care 2004;27:1047-53.

[2]. Das T ,Jalai S,VedantamV, Majji AB. Retinal vascular disorders. In :Saxena S [Ed]:Clinical Practice in Ophthalmology. New Delhi, JP Brothers 2003:pp 350.

[3]. Bresnick GH. Diabetic macular edema: a review. ophthalmology 1986;-93:989-97.

[4]. 4.Risk factors for CSME in a multi ethnics population with Type 2 diabetes Ong Ming Jew, Mohammadreza Peyman et al, I J of Ophthalmology,08/2012;5[4];499-504.

[5]. 5.Association of systemic risk factors with the severity of retinal hard exudates in a north Indian population with type 2 diabetes. $\mathrm{N}$ Sachdev, A Sahni et al, J 1Postgrad Med 2010;56:3-6. 